\title{
Study on the Problems and Countermeasures in the Research Work of Teachers of Elementary Courses in Agricultural and Forestry Colleges and Universities
}

\author{
Yuci Wang \\ Beijing University of Agriculture \\ Beijing 102206
}

\begin{abstract}
There are lots of problems in the research work of elementary courses teachers, for example professional background of elementary courses teachers is unfavorable to the application for research projects; the time and effort spending in research are influenced by overloaded teaching tasks; poor experimental condition is not conducive to the research and the limitation of education background and professional title restrict them to research. Therefore, by analyzing these problems, this paper puts forward some solutions: elementary courses teachers should deal well with the relationship between teaching and research; research plan should be confirmed in accordance with professional courses; elementary courses teachers can cooperate with professional courses teachers to conduct research; suitable evaluation of professional title and awarding policies of research should be formulated and the emphas is on elementary disciplines can create favorable research environment.
\end{abstract}

Keywords-agricultural and forestry colleges and universities; elementary courses; research work; problems; countermeasures

\section{INTRODUCTION}

Elementary courses teachers in agricultural and forestry colleges refer to the teachers of public elementary courses engaging in the teaching of English, physical education, mathematics, foreign languages, computer, chemistry, ideological and political education, etc. who account for a major percentage in agricultural and forestry colleges and undertake one third to a half of theoretical teaching task of each major in colleges. Therefore, they play a vital role in improving teaching quality and cultivating talents in institutions of higher learning. However, elementary courses teachers have no advantages in the application for research projects. To take Beijing University of Agriculture as an example, from January to October of 2017, the research funds totaled 54.33 million Yuan with only 215,000 Yuan of research funds for elementary courses teachers, which means that the research funds of elementary courses teachers accounting for more than one tenth of all faculty in school is less than four thousandths of the faculty. The difficulties for elementary courses teachers to apply for research projects, have academic achievements and promote in their professional titles have become the bottleneck to restrict their development, which has negative influence on their working enthusiasm and personal development prospect.

\section{Problems in the Research Work of Elementary Courses Teachers in Agricultural and Forestry COLLEGES AND UNIVERSITIES}

\section{A. The professional background of elementary courses teachers is unfavorable to the application for research projects}

Most elementary courses teachers graduate from comprehensive universities which are mainly 985 and 211project key universities. Compared with professional courses teachers in agricultural and forestry colleges, they have a solid foundation in theoretical knowledge and comprehensive capacity and are strong in the ability of thinking and experimental skills. But there is a gap between their professional background and the characteristics and orientation of colleges. For example, Beijing University of Forest aims to cultivate comprehensive and practice talents for modern agriculture and forestry and makes great effort to create and perfect higher education system of modern agriculture. The main majors are gardening, agronomy, biology, animal medicine, agro-forestry economics and management, landscape architecture, food science and engineering, etc. Elementary courses teachers mainly teach English, Mathematics, physics, chemistry, computer, physical education, etc. And they are unfamiliar with each major and hard to integrate into the professional system. Thus, it is difficult for them to get support from superior research departments when they are engaged in researching. And the characteristics of elementary courses such as mathematics and physics decide that it is hard to innovate professionally because the contents of these subjects are already fixed after hundreds of thousands years of knowledge inheritance. The course of computer comes into being very late, but its knowledge updates so fast that learning pace lags behind the speed of development. The relative matureness of content makes it hard to innovate, thus it cannot keep up with the frontier of knowledge. When teachers apply for research projects on elementary courses such as English, physical education and ideological and political education, it is usually harder to compare with that of agro-forestry disciplines. The research projects in agricultural and forestry colleges and universities mainly focus on the orientation of agro-forestry, 
which puts elementary courses teachers in an obvious inferior position in applying for research projects. If they commit themselves to the theoretical study of their own majors, then research conditions, document literature and information sources are inferior to those in comprehensive colleges.[1] Therefore, the professional background of elementary courses teachers puts them in an unfavorable position in the application for research projects in agro-forestry colleges and universities.

\section{B. The time and effort spending in research are influenced by overloaded teaching tasks}

The elementary courses teachers in agro-forestry colleges undertake lots of teaching task. Compared with professional courses, elementary courses with more class hours emphasize classroom teaching and a lot of homework are assigned in the class of math, English, chemistry, physics, etc. And teachers are occupied by teaching. However, professional courses mainly emphasize practice with a great deal of experiment work, which is obviously much easier than that of elementary courses teachers. The teaching task of elementary courses goes through the whole academic year. Multiple teachers can teach the same subject with the unchanged teaching objectives. They usually have no time to travel for investigation or attend academic seminar. To take basic teaching department of Beijing University of Agriculture as an example, there are 12 teachers in teaching and research room of math. In 2017, the teaching quantity is 7,648 classes with an average of annual quantity 673 classes per capita and 20 classes per week. With such overloaded teaching task, elementary courses teachers are hard to spare enough effort to research.

\section{Poor experimental condition is not conducive to the research}

Colleges pay much more attention to the laboratories of professional courses than that of elementary courses. The main purpose of instruments in the teaching and research room and laboratories of elementary courses is to maintain the regular need of teaching and experiment. Thus they are unable to compare with those in the laboratories of professional courses, to say nothing of those in professional scientific research institutions. Therefore, it is very difficult for elementary courses teachers to get major theoretical research projects at ministerial and provincial-level and national level.[2] To take basic teaching department of Beijing University of Agriculture for an example, there are 7 teachers and 3 experiment personnel in teaching and research room of chemistry. The area of laboratory is 777 square meters with fixed assets of more than 10 million. Teaching and research room of chemistry undertakes 3,000 experimental classes every year, thus laboratories are hard to meet the need of teaching unless the experimental classes are arranged from 8 am to $10 \mathrm{pm}$. Additionally, due to insufficient laboratories and shortage of instruments, elementary courses teachers lack the basic facilities to conduct research and study.

\section{The limitation of education background and professional title restrict them to research}

Compared with professional courses teachers, elementary courses teachers are in a clear unfavorable position in the aspect of education background and professional title. To take Beijing University of Agriculture as an example, teachers in basic teaching department all have master degree but no one has doctor degree. There are only 3 professors among 48 fulltime teachers, which cannot compare with those of professional courses with doctor degree. Therefore, low education background and professional title of elementary courses teachers encounter lots of difficulties in applying for research projects. In turn, less research projects and academic achievements have negative influence on the promotion of professional title for elementary courses teachers. Thus, a vicious circle comes into being in which elementary courses are in an inferior position in the field of research. And low professional title and income have an impact on working enthusiasm for elementary courses teachers, which is not conducive to improve teaching quality.

\section{Solutions to the PROBlems IN THE Research Work OF ELEMENTARY COURSES TEACHERS}

\section{A. Elementary courses teachers should deal well with the relationship between teaching and research.}

The responsibility of elementary courses teachers is not only to impart basic theoretical knowledge and experimental skills, but also to teach students to innovate by using what they have learned, cultivate their awareness of innovation and creative talent and improve their abilities to analyze and solve problems. Therefore, elementary courses teachers not only have richtheoretical knowledge, but also have sufficient research experience and are equipped with sound research methods and stronger research capacity. On the one hand, elementary courses teachers can introduce scientific research into teaching process, bring their own or others' advanced achievements of research to the content of courses and impart latest scientific knowledge and information into students, which not only makes students get to know the most advanced academic information of their own disciplines and majors in time and the orientation and progress of research development, but also optimizes curriculum system and teaching material system and is conducive to motivate students' study initiative and cultivate their innovational thinking and creative talent. On the other hand, elementary courses teachers should be good at finding problems in teaching and solve these problems from the perspective of research, which can provide ideas for their research and broaden the sources of research topics. Elementary courses teachers should attach importance to the mutual relationship between teaching and research, which is dialectical unity and coordinated development. Neither should be neglected or else it is not conducive to the growth of elementary courses teachers and the improvement of teaching quality. Research is the premise and foundation of teaching and teaching requires research to improve, both of which are supplement each other and indispensable.[3]

\section{B. Research plan should be confirmed in accordance with professional courses}

Elementary courses teachers should pinpoint their positions and confirm research plan in the light of their own reality when they conduct research. Based on their own disciplines and 
combining with majors of agro-forestry colleges and universities, elementary courses teachers should constantly close to the disciplines of agro-forestry, conduct applied research of basic theory in the field of agriculture and make great effort in the study of inter-discipline between elementary and professional courses and theoretical disciplines and applied technological disciplines. For instance, the subject of chemistry can be used in the monitoring research of pesticide residue and in the sustained-release and control of fertilizer and pesticide. The subject of physics can be used in the applied research of physical theory and technology in relevant fields. Specifically speaking, electromagnetic wave attenuation principle can be applied in the determination of soil moisture. Temperature sensor can measure the temperature of canine animals, to name just a few of such research. The subject of math can be used in the applied study of mathematic model in related disciplines. In order to better conduct applied research of basic theory in related disciplines, elementary courses teachers should not only learn new theoretical knowledge and development trend of their own disciplines, but also work hard to learn agricultural majors they are interested in and relevant professional courses, which can combine elementary courses with professional courses in teaching in a better manner, serve professional courses and facilitate elementary courses teachers to further explore research projects and key orientation of basic theoretical knowledge applied in professional courses.

\section{Elementary courses teachers can cooperate with professional courses teachers to conduct research}

Elementary courses teachers master abundant basic theoretical knowledge and have stronger experimental skills, while professional courses teachers are familiar with professional field and easy to get research project and funds. Elementary courses teachers and professional courses teachers should work together to research, draw on each other's strength and give play to each other's' advantages, thus being easier to have academic achievements.[4] Professional courses teachers often encounter such research issues as involve multiple disciplines in their research. Although they have solid theoretical foundation, sometimes these problems are so difficult that they require elementary courses teacher to work with. In today's research, both elementary research and applied research are transferred from past qualitative description to quantitative calculation. And the characteristic and advantage of elementary disciplines are quantitative calculation. For example, in research projects, math teachers can undertake the task of establishment of mathematic model, data processing and analog computation. Physics teachers can conduct the analysis of the characteristic of dynamics. Software production can be done by using computer. Chemistry teachers can be responsible for chemical reagent analysis, optimal design of experiment, etc. All of these are the advantages of elementary courses teacher. The joint research conducted by elementary courses teachers and professional courses teachers can achieve win-win target. Leaders in colleges and departments should figure out to integrate each discipline, set up resource sharing mechanism through broad cooperation of each majors of schools and build research mechanism of interdisciplinary cooperation and team, thus providing more research opportunities for elementary courses teachers.

\section{Suitable evaluation of professional title and awarding policies of research should be formulated}

Leaders at college and school level should combine the characteristics of elementary courses teachers to formulate corresponding policies and motivate teachers to research. Most of elementary courses teachers focus on teaching while are poor at research, therefore comprehensive evaluation should be used to evaluate elementary courses teachers, which means that both research and academic ability and teaching result and teachers own professional competence should be taken into consideration. Thus a fair and reasonable evaluation system should be formulated. In the evaluation of professional title, it should lower the level or number of the achievements of research in a proper manner, set up teaching-based, researchbased and teaching \&research-based senior professional title and make elementary courses teacher choose teaching, research or both of them by themselves in accordance with their own characteristics. Those who have good performance in teaching can spend their effort and time in teaching and undertake more teaching task while those who excel in research can spare their effort on research and reduce corresponding teaching task. Thus, elementary courses teachers can adopt others' good points and avoid their own shortcomings, give full play to their own advantages and make up for their shortcomings. As for teachers with senior professional title, it should prevent such attitude as holds that they can teach once and for all from happening and enhance the percentage of research in annual review. In performance assessment and excellent faculties selection, it should take into account the characteristics of elementary courses teachers, formulate standard and policies different from professional courses teacher and allow the differences of teaching ability, research ability and teaching style among teachers on the premise of guaranteeing the quality of teaching and research, thus motivating the working enthusiasm of elementary courses teachers.[5] In addition, it should combine the characteristics of elementary courses teachers to study quantitative criteria of teaching which should be scientific and operable, formulate evaluation criterion of teaching in comparison with the value of research achievements, build incentive policy of harmonious development between teaching and research and stimulate the teaching and research initiative of elementary courses teachers. Meanwhile, it should guarantee the continuous improvement of teaching quality and promote elementary courses teachers actively engaging in research.

\section{E. The emphasis on elementary disciplines can create favorable research environment.}

Leaders of colleges should recognize the importance of elementary courses teachers in research, thus it can increase input to create favorable research environment for elementary courses teachers. It should strengthen the construction of the laboratories of elementary courses, increase experimental fields and instruments and provide more favorable experimental environment for elementary courses teachers on the premise of ensuring experimental condition of teaching. Leaders of colleges can invite well-known experts and scholars to colleges to do academic report, update the latest development and progress, and employ experts to train young teachers on the application of research projects and the writing of high-level 
theses. Additionally, it should encourage elementary courses teachers to actively attend academic exchange at home and abroad, broaden academic horizon of elementary courses teacher and cultivate their initiative in participating in research. And leaders of colleges should also encourage young teachers to further study for higher degree, provide the opportunities of study at home and abroad and continuing education for young teachers and create favorable conditions for the career development of young teachers.

\section{REFERENCES}

[1] Wang Zhengzhou. How to Conduct Research for Elementary Course Teachers in Agricultural Colleges and Universities[J]. Higher Agricultural Education, 1993(6):49-50.

[2] Sun Zaichun, Zhang Zailong. How to Deal With the Relationship Between Teaching and Research in the Teaching and Research Room of Elementary Courses[J]. Petroleum Education, 1996(10):17-19.

[3] Chen Lifang, Chen Liang. How to Deal With Relationship Between Research and Teaching Properly for Basic Course Teachers[J]. Journal of Hebei United University (Social Science Edition), 2013,1(1):63-66.

[4] Nan Duguo. Study on How to Conduct Research for Elementary Courses Teachers[J]. Heilongjiang Researches on Higher Education, 1996(5):8990.

[5] Sun Xiaofei. Relief Job Tiredness and Improvement of Research and Teaching Level: Based on the Empirical Study of Public Elementary Courses Teachers in the Department of Medicine in a College[J]. Chinese Journal of Medical Science Research Management, 2014,8(4):429-433. 